\title{
Redox regulation of methylthioadenosine phosphorylase in liver cells: molecular mechanism and functional implications
}

\author{
Joaquín FERNÁNDEZ-IRIGOYEN*, Mónica SANTAMARÍA*, Virginia SÁNCHEZ-QUILES*, Maria U. LATASA*, Enrique \\ SANTAMARÍA*, Javier MUÑOZ*, Manuel M. SÁNCHEZ DEL PINO†, María L. VALERO†, Jesús PRIETO*, Matías A. ÁVILA*1 \\ and Fernando J. CORRALES ${ }^{* 1,2}$ \\ *Division of Hepatology and Gene Therapy, Center for Applied Medical Research (CIMA), University of Navarra, 31008 Pamplona, Spain, and †Proteomics Laboratory, \\ Príncipe Felipe Research Center (CIPF), 46012 Valencia, Spain
}

\begin{abstract}
MTAP (5'-methylthioadenosine phosphorylase) catalyses the reversible phosphorolytic cleavage of methylthioadenosine leading to the production of methylthioribose-1-phosphate and adenine. Deficient MTAP activity has been correlated with human diseases including cirrhosis and hepatocellular carcinoma. In the present study we have investigated the regulation of MTAP by ROS (reactive oxygen species). The results of the present study support the inactivation of MTAP in the liver of bacterial LPS (lipopolysaccharide)-challenged mice as well as in HepG2 cells after exposure to t-butyl hydroperoxide. Reversible inactivation of purified MTAP by hydrogen peroxide results from a reduction of $V_{\max }$ and involves the specific oxidation of Cys ${ }^{136}$ and Cys ${ }^{223}$ thiols to sulfenic acid that may be further stabilized to sulfenyl amide intermediates. Additionally, we found that Cys ${ }^{145}$ and
\end{abstract}

Cys $^{211}$ were disulfide bonded upon hydrogen peroxide exposure. However, this modification is not relevant to the mediation of the loss of MTAP activity as assessed by site-directed mutagenesis. Regulation of MTAP by ROS might participate in the redox regulation of the methionine catabolic pathway in the liver. Reduced MTA (5'-deoxy-5'-methylthioadenosine)-degrading activity may compensate for the deficient production of the precursor $S$-adenosylmethionine, allowing maintenance of intracellular MTA levels that may be critical to ensure cellular adaptation to physiopathological conditions such as inflammation.

Key words: cysteine oxidation, inflammation, methylthioadenosine, methylthioadenosine phosphorylase, oxidative stress, sulfenic acid.

\section{INTRODUCTION}

MTA (5'-deoxy-5'-methylthioadenosine) is a sulfur-containing nucleoside that is present in all cell types including prokaryotes, yeast, plants and higher eukaryotes. In mammalian tissues MTA is generated from its precursor, decarboxylated SAM ( $S$-adenosylmethionine), during the synthesis of polyamines spermine and spermidine [1] or, alternatively, from the spontaneous splitting of SAM under physiological conditions [2]. Although MTA has been known for more than a century, its biological importance was first proposed in 1952 [3]. The enzyme-catalysed conversion of MTA into adenine and MTR1P (5-methylthioribose-1-phosphate) provides the first and rate-limiting step in purine and methionine salvage pathways. MTR1P is recycled into methionine and adenine is used to replenish the AMP and ATP pools [3]. Additionally to its central role in cellular metabolism, MTA also participates in the regulation of a wide variety of cellular functions. Intracellular fluctuations in MTA levels could participate in the regulation of proliferative responses [4], as well as in the modulation of inflammatory responses [5]. These effects might be mediated by its inhibitory effect on polyamine biosynthesis [6], by its capacity to interfere with key signalling pathways through the inhibition of growth-factor-induced protein tyrosine phosphorylation and cAMP phosphodiesterase [7], and by the inhibition of protein methylation [3], a well-known post-translational modification involved in the modulation of cellular signalling and gene expression. Therefore it appears clear that regulation of MTA levels is crucial to preserve cellular homoeostasis. This concept is further reinforced by studies suggesting the therapeutic potential of this natural compound in different diseased conditions [8,9].

MTAP (5'-methylthioadenosine phosphorylase; 5'-deoxy5 '-methylthioadenosine:orthophosphate methylthioribosyltransferase; EC 2.4.2.28) catalyses the reversible phosphorolytic cleavage of MTA leading to the production of MTR1P and adenine [10]. After the original description of this enzymatic activity, MTAP has been purified and characterized from different organisms and tissues [11,12]. Biochemical and structural evidence indicate that mammalian MTAP is a trimer consisting of three identical subunits of $32 \mathrm{kDa}$ [13] that in humans contain 283 amino acid residues. MTAP is abundantly expressed in normal cells and tissues [14] where it accounts for the production of most of the free adenine generated in human cells [15]. In contrast, lack of MTAP activity is frequently observed in tumour cells [16]. The MTAP gene has been mapped to human chromosome 9 p21 [14] in a region that is often deleted in tumour cells. In most cases, it appears that the loss of MTAP activity or mRNA is the result of homozygous deletions of the MTAP gene [17]. However alternative mechanisms must also exist since MTAP impairment was detected in lymphoma and melanoma-derived cell lines with an intact MTAP gene [18,19]. The presence of a $\mathrm{CpG}$ island proximal to the transcription start site of the MTAP promoter [18]

Abbreviations used: DMEM, Dulbecco's modified Eagle's medium; DTNB, 5,5'-dithiobis-(2-nitrobenzoic acid); DTT, dithiothreitol; GPS, gentamicinpenicillin-streptomycin; HO-1, haem oxygenase 1; LPS, lipopolysaccharide; MALDI-TOF-MS, matrix-assisted laser-desorption ionization-time-of-flight MS; MAT, methionine adenosyltransferase; MTA, 5'-deoxy-5'-methylthioadenosine; MTAP, 5'-methylthioadenosine phosphorylase; MTR1P, 5-methylthioribose1-phosphate; NBD-Cl, 4-nitrobenzo-2-oxa-1,3-diazole; ROS, reactive oxygen species; SAH, S-adenosylhomocysteine; SAM, S-adenosylmethionine; TNB, thiobis-(2-nitrobenzoic acid); WT, wild-type.

1 These authors share senior authorship.

2 To whom correspondence should be addressed (email fjcorrales@unav.es). 
has recently been reported, suggesting a transcriptional regulation of the gene through a methylation/demethylation mechanism. This notion was confirmed in HCC (hepatocellular carcinoma) cell lines showing down-regulation of MTAP gene expression that could not be attributed to genomic losses or mutations but to promoter hypermethylation [20]. Additionally, it has been found that the transcriptional activation of the human MTAP gene is mediated by the binding of the CCAAT binding factor to a distal CCAAT motif in the promoter [21]. Besides the regulation at the transcriptional level, there is also evidence suggesting modulation of MTAP activity. Phosphorylation of $\operatorname{Ser}^{183}$ and Thr ${ }^{188}$ residues have been recently reported, although the biological transcendence of these modifications must be demonstrated [22]. Oxidation also arises as a mechanism to modulate MTAP activity as suggested by the requirement of the enzyme for thiol-reducing agents and its specific and rapid inactivation by thiol-blocking groups [23]. However, although the implication of cysteine residues in the stabilization of the MTAP protein from hyperthermophilic organisms through the formation of disulfide bridges has been established [24], the role of specific thiols in the modulation of MTAP activity is less evident.

In the present study we provide data supporting MTAP inactivation in the liver of mice after induction of an inflammatory reaction by administration of LPS (lipopolysaccharide). Reduction of MTAP activity was also demonstrated in MTAP-expressing HepG2 cells after exposure to t-butyl hydroperoxide. Reversible inactivation of MTAP by ROS (reactive oxygen species) occurs by specific oxidation of $\mathrm{Cys}^{136}$ and $\mathrm{Cys}^{223}$ to sulfenic acid as illustrated by the loss of sensitivity of mutants in which these residues were substituted by a serine residue. MTAP inactivation by ROS arises then as a specific regulatory mechanism that might be pivotal in cellular adaptation to physiological or pathological conditions, such as inflammation, that involve oxidative stress.

\section{MATERIALS AND METHODS}

\section{Animal experiments}

Male C57B16 mice (mass of 19-21 g) were from Harlan. Studies were approved by the University of Navarra Committee on Animal Care and satisfied National Institutes of Health guidelines for humane treatment of animals. Mice were injected intraperitoneally with $15 \mathrm{mg} / \mathrm{kg}$ of endotoxin (Salmonella typhimurium LPS; Sigma) dissolved in sterile, pyrogen-free saline. Liver tissue was removed after $22 \mathrm{~h}$, snap-frozen in liquid nitrogen and stored at $-80^{\circ} \mathrm{C}$ until analysis.

\section{SAM, SAH ( $S$-adenosylhomocysteine) and MTA measurements}

Liver samples $(50 \mathrm{mg})$ were homogenized in $250 \mu \mathrm{l}$ of $0.4 \mathrm{M}$ perchloric acid. Homogenates were centrifuged at $10000 \mathrm{~g}$ at $4{ }^{\circ} \mathrm{C}$ for $15 \mathrm{~min}$. SAM, SAH and MTA levels were measured in the supernatant by HPLC as described previously [25]. Then, $100 \mu \mathrm{l}$ aliquots were loaded on to a Bio-Sil ${ }^{\circledR}$ ODS-5S column equilibrated in $0.01 \mathrm{M}$ ammonium formate and $4 \mathrm{mM}$ heptanesulfonic acid (pH 4.0). MTA was eluted with a linear gradient (25-100\%) acetonitrile in the same buffer. Chromatograms were analysed with the software 32 Karat 5.0 (Beckman Coulter).

\section{Cell transfection}

SK-Hep1 cells grown in 60-mm dishes until $70 \%$ confluence were transfected with a pcDNA3.1 HisA plasmid harbouring the complete human MTAP cDNA, or the empty pcDNA3.1 HisA vector. Transfections were carried out using Tfx-1 (Promega) according to the manufacturer instructions, and transfectants were selected in complete medium containing $0.6 \mathrm{mg} / \mathrm{ml}$ of $\mathrm{G} 418$ sulfate (Geneticin; Invitrogen) as described previously [26]. After two weeks, individual colonies were harvested, and clones were transfected with the empty vector pcDNA3.1 HisA (SK-EV) or the MTAP-expressing construct (SK-WT) were expanded.

\section{MTAP activity in liver cell lines}

HepG2 or SK-Hep1 cells $\left(10^{6}\right)$ were plated on $60 \mathrm{~mm}$ dishes and were incubated with DMEM (Dulbecco's modified Eagle's medium) supplemented with $10 \%$ FBS (foetal bovine serum), $1 \%$ GPS (gentamicin-penicillin-streptomycin) and $0.6 \mathrm{mg} / \mathrm{ml}$ G418. Then, after cell adhesion, cells were incubated overnight with DMEM without methionine and supplemented with $10 \%$ horse serum and $1 \% \mathrm{GPS}$, at $37^{\circ} \mathrm{C}$ and $5 \% \mathrm{CO}_{2}$. Then, after 40 min incubation with the indicated concentration of t-butyl hydroperoxide at $37^{\circ} \mathrm{C}, 16 \mu \mathrm{M}$ MTA was added to the culture medium. MTA consumption was determined by measuring the extracellular MTA remaining after different incubation periods as described above.

\section{MTAP cloning and site-directed mutagenesis}

Total human resting peripheral blood lymphocyte RNA was isolated using the guanidinium thiocyanate method [27] and was transcribed to cDNA using the Superscript pre-amplification system (Invitrogen). The cDNA was amplified using Taq Long Plus enzyme (Stratagene) and the sense (5'-CTCGAGATCTGCATGGCCTCTGGCACC-3') and antisense (5'-ATGAATTCCTTAATGTCTTGGTAATAAAAC-3') primers, derived from the human MTAP subunit cDNA sequence. The PCR products were purified using the QIAquick Gel Extraction kit (Qiagen) and ligated into the expression vector pCDNA3.1, according to the manufacturer's instructions (Eukaryotic TA cloning Kit Unidirectional; Invitrogen) or into the plasmid pRSETA (Invitrogen), resulting in constructs that include a 5'-sequence coding for six histidine residues and a protease-cleavage site in-frame with the human MTAP-coding region. Cysteine replacement by a serine residue was performed by site-directed mutagenesis with the QuikChange ${ }^{\circledR}$ site-directed mutagenesis kit (Stratagene) using the primers indicated in Supplementary Table 1 (at http://www.BiochemJ.org/bj/411/bj4110457add.htm). The cloned products and all mutants were confirmed by sequencing the complete MTAP cDNA. Stable transfectants of each MTAP mutant were established in SK-Hep1 cells as described above.

\section{Expression and purification of recombinant MTAP}

Recombinant WT (wild-type) and MTAP mutants were expressed in Escherichia coli BL21(DE3) (Invitrogen) as described previously [28]. Cells were homogenized in $100 \mathrm{mM}$ Tris/ $\mathrm{HCl}(\mathrm{pH} \mathrm{8})$, $0.5 \mathrm{M} \mathrm{NaCl}$ with $1 \mathrm{mM}$ benzamidine, $1 \mathrm{mM}$ PMSF and $0.5 \mathrm{mg} /$ $\mathrm{ml}$ lysozyme. After $30 \mathrm{~min}$ incubation on ice, cell extracts were obtained by sonication and the cytosolic fraction was separated by ultracentrifugation at $75000 \mathrm{rev} . / \mathrm{min}$ (rotor TLA 100.2; Beckman) at $4{ }^{\circ} \mathrm{C}$ for $1 \mathrm{~h}$. Recombinant WT and MTAP mutant proteins were purified from the bacterial cytosolic extracts by affinity chromatography on a $\mathrm{Ni}^{2+}$-Sepharose column (GE Healthcare) equilibrated in $50 \mathrm{mM}$ Tris/ $\mathrm{HCl}(\mathrm{pH} 8), 0.5 \mathrm{M} \mathrm{NaCl}$ and $40 \mathrm{mM}$ imidazole. After washing with 10 column volumes of equilibration buffer, elution was performed with a linear gradient from $40 \mathrm{mM}$ to $1 \mathrm{M}$ imidazole in the same buffer. Histagged MTAP proteins eluted from the $\mathrm{Ni}^{2+}$ column at $250 \mathrm{mM}$ 
imidazole. Protein purity was always more than $95 \%$ as estimated by SDS/PAGE [29]. MTAP-containing fractions were pooled, desalted with $5 \mathrm{ml}$ HiPrep desalting columns (GE Healthcare) and the protein concentration was determined using the Bio-Rad protein assay kit based on the Bradford assay [30]. The purified protein was then stored at $-80^{\circ} \mathrm{C}$ in the presence of $5 \mathrm{mM}$ DTT (dithiothreitol). Enterokinase processing was performed using the Enterokinase Max assay (Invitrogen) according to the manufacturer's protocol.

\section{MTAP activity assays}

DTT was removed from the preparation with HiPrep desalting columns equilibrated in $10 \mathrm{mM}$ Tris/ $\mathrm{HCl}(\mathrm{pH} \mathrm{7.4)}$ and $10 \mathrm{mM}$ $\mathrm{KCl}$ immediately before use. Two independent procedures were used to measure the activity of purified WT and MTAP mutant proteins. The reaction mixture always contained $1 \mu \mathrm{M}$ MTAP protein or liver homogenates (400 $\mu \mathrm{g}$ of total protein) in $50 \mathrm{mM}$ phosphate buffer ( $\mathrm{pH}$ 7.4) and the appropriate concentration of MTA in a final volume of $400 \mu$ l. Pre-incubation with $5 \mathrm{mM}$ DTT or different $\mathrm{H}_{2} \mathrm{O}_{2}$ concentrations was performed as indicated. The mixture was then incubated at $37^{\circ} \mathrm{C}$ for the indicated period of time and the reaction was stopped with perchloric acid to a final concentration of $0.4 \mathrm{M}$. MTA measurements were performed by HPLC as indicated previously. Alternatively, MTAP activity was determined according to the procedure described by Singh et al. [31]. Conditions were as described above. The reaction was started by the addition of MTA and consumption was followed by the reduction of the absorbance at $275 \mathrm{~nm} . \mathrm{H}_{2} \mathrm{O}_{2}$ was added when required to the enzyme and the mixture was incubated for $10 \mathrm{~min}$ at $37^{\circ} \mathrm{C}$ before adding MTA. Time-course assays were performed in the presence of different concentrations of MTA and initial velocity values were obtained in each case from the linear fitting of the MTA variation in the first $3 \mathrm{~min}$ of the reaction. $V_{\mathrm{i}}$ against MTA concentration plots were fitted to the Michaelis-Menten equation using Kaleidograph 3.5b5.

\section{Quantification of free thiol groups and sulfenic derivatives}

Purified MTAP was pre-incubated for 5 or $30 \mathrm{~min}$ with DTT or the appropriate concentration of $\mathrm{H}_{2} \mathrm{O}_{2}$ that were subsequently eliminated with a HiPrep desalting column equilibrated in $50 \mathrm{mM}$ phosphate buffer ( $\mathrm{pH} 7.4)$. Free thiol groups were quantified by incubation with DTNB [Ellman's reagent; 5,5'-dithiobis-(2nitrobenzoic acid)] following the absorbance at $412 \mathrm{~nm}$ resulting from the liberation of TNB [thiobis-(2-nitrobenzoic acid)] after interaction with sulfhydryl groups. The DTNB reaction was performed in a final volume of $400 \mu \mathrm{l}$ containing $50 \mathrm{mM}$ phosphate buffer ( $\mathrm{pH} 7.4$ ), $1 \mathrm{mM}$ EDTA, $6 \mathrm{M}$ guanidinium chloride, $25 \mu \mathrm{M}$ protein and $20 \mathrm{mM}$ DTNB. The amount of accessible sulfhydryl groups was calculated by measuring the TNB released using a molar extinction coefficient of $13600 \mathrm{M}^{-1} \cdot \mathrm{cm}^{-1}[32,33]$. Determination of sulfenic acid from cysteine $\mathrm{SH}$ oxidation was performed using two different approaches. In the first method, sulfenic acid was titrated with TNB according to the procedure described by Poole et al. [34]. Protein samples prepared as indicated above were incubated with $20 \mathrm{mM}$ TNB at $25^{\circ} \mathrm{C}$ for $30 \mathrm{~min}$. The excess of TNB was then removed with HiPrep desalting columns under the same conditions described above. DTT was added $(50 \mathrm{mM})$ to release the TNB associated to $\mathrm{SOH}$ groups that was measured by absorbance at $412 \mathrm{~nm}$. Alternatively, NBD-Cl (4-nitrobenzo-2-oxa-1,3-diazole; $20 \mathrm{mM}$ ) was used following the procedure described previously [35]. NBD-Cl was added to protein preparations and the mixture was incubated at $25^{\circ} \mathrm{C}$ for $30 \mathrm{~min}$. After elimination of the NBD-Cl excess with HiPrep desalting columns, SH-derived adducts and sulfenic resulting derivatives were measured at 420 and $347 \mathrm{~nm}$ respectively.

\section{Size-exclusion chromatography}

WT and MTAP mutants were chromatographed in a Superdex$200 \mathrm{HR} 10 / 30$ column (GE Healthcare) equilibrated in $50 \mathrm{mM}$ Tris/ $\mathrm{HCl}$ (pH 7.5). Isocratic elution with the same buffer $(0.8 \mathrm{ml} /$ min) was monitored at $280 \mathrm{~nm}$. The column was calibrated in the same conditions using catalase $(232 \mathrm{kDa})$, BSA $(67 \mathrm{kDa})$, trypsin $(21 \mathrm{kDa})$ and ribonuclease $\mathrm{A}(13.7 \mathrm{kDa})$ as standards. Alternatively MTAP was denatured by $2 \mathrm{~h}$ incubation with $6 \mathrm{M}$ guanidinium chloride after the indicated treatments. Unfolded proteins were then analysed with the same column equilibrated in $100 \mathrm{mM}$ Tris/ $\mathrm{HCl}(\mathrm{pH} 3.0)$ and $6 \mathrm{M}$ guanidinium chloride.

\section{MS analysis}

Samples of MTAP protein (50-100 $\mu \mathrm{g}$ ) were incubated with $500 \mu \mathrm{M} \mathrm{H} \mathrm{H}_{2} \mathrm{O}_{2}$ or $5 \mathrm{mM}$ DTT and subsequently prepared for MALDI-TOF-MS (matrix-assisted laser-desorption ionizationtime-of-flight MS) analysis (MALDI TOF GL-REF mass spectrometer; Waters). After desalting to eliminate excess $\mathrm{H}_{2} \mathrm{O}_{2}$ or DTT, free cysteine residues were alkylated by a reaction with $100 \mathrm{mM}$ iodoacetamide for $30 \mathrm{~min}$ and the protein was precipitated in chloroform/methanol (4:1). Protein pellets were resuspended in $25 \mathrm{mM}$ ammonium bicarbonate and incubated with $2 \mu \mathrm{l}$ of $50 \mu \mathrm{g} / \mu \mathrm{l}$ trypsin (Promega) at $37^{\circ} \mathrm{C}$ for $12 \mathrm{~h}$. Alternatively, the protein was dissolved in $10 \mathrm{mM}$ Tris/ $\mathrm{HCl}$ (pH 7.8), $10 \mathrm{mM}$ calcium chloride and incubated with $2 \mu \mathrm{l}$ of $25 \mu \mathrm{g} / \mu \mathrm{l}$ chymotrypsin (Roche) at $25^{\circ} \mathrm{C}$ for $12 \mathrm{~h}$. Half of the sample was then reduced with $10 \mathrm{mM}$ DTT at $55^{\circ} \mathrm{C}$ for $30 \mathrm{~min}$. The digestion mix was desalted with reversed-phase C18-ZipTip (Millipore). Then $1 \mu \mathrm{l}$ of the resulting solutions were mixed with an equal volume of CHCA ( $\alpha$-cyano- 4 hydroxy-trans-cynnamic acid) in $50 \%$ acetonitrile with $0.1 \%$ TFA (trifluoroacetic acid) and spotted on to a MALDI target plate. The system was calibrated daily with a tryptic digest of ADH (alcohol dehydrogenase), and after analysis nearpoint calibration was performed using corticotrophin [ACTH (adrenocorticotrophic hormone)] as the lock-mass standard. Data processing was performed with Masslynx release 4.0 (Waters) to subtract background noise using polynomial order 10 with $10 \%$ of the data points below this polynomial. Data were also smoothed by one smooth operation (Savitzky Golay) with a window of two channels. MS spectra were processed automatically with MASCOT and then interpreted by manual inspection using Masslynx 4.0 (Waters). The presence of disulfide bridges was analysed using MS-Bridge 4.0.8 from the Protein prospector webpage (http://prospector.ucsf.edu/).

\section{Western blot analysis}

Liver tissues and cultured cells were lysed and proteins were extracted as previously described [7]. Equal amounts of protein $(20 \mu \mathrm{g})$ were resolved using SDS/PAGE (12.5\% gels). Proteins were electrophoretically transferred on to nitrocellulose membranes for $45 \mathrm{~min}$ at $120 \mathrm{~V}$. Membranes were probed with a 1:5000 or 1:1000 dilution of anti-MTAP (the gift of Dr D.A. Carson, University of California, San Diego, U.S.A.) or anti-(HO1) (haem oxygenase 1; Stressgene) antibodies respectively. Antichicken and anti-rabbit IgG peroxidase-conjugated secondary antibodies were used for MTAP and HO-1 assays. Blots were developed by enhanced chemiluminiscence (PerkinElmer). 


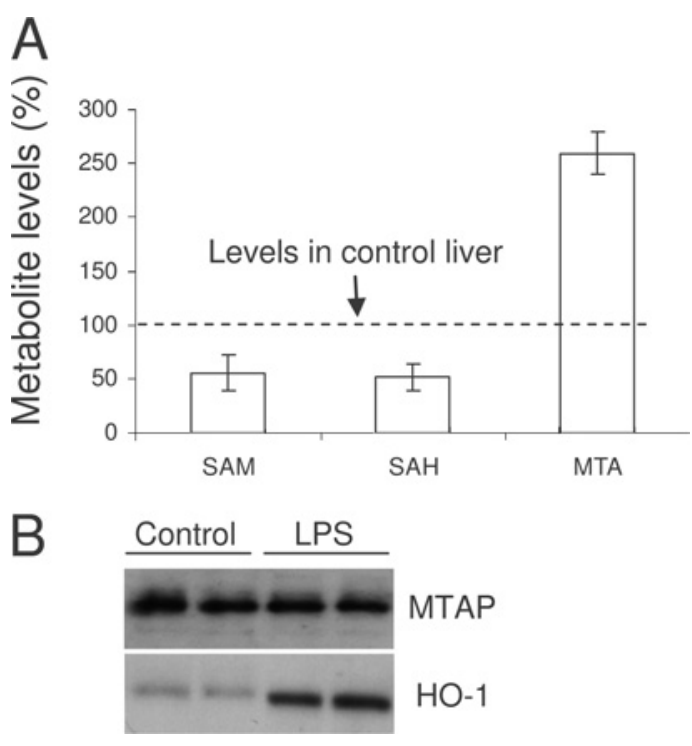

Figure 1 MTAP inactivation in the liver of LPS challenged mice

(A) Hepatic levels of SAM, SAH and MTA in LPS-treated mice are represented as the percentage of control values $(100 \%)$ measured in saline-injected animals ( $n=6$ per condition). The $100 \%$ values were $38 \pm 6.12,12 \pm 1.5$ and $4.2 \pm 1.1 \mathrm{pmol} / \mathrm{mg}$ of protein for SAM, SAH and MTA respectively. (B) Levels of MTAP and H0-1 proteins were determined in control and LPS-challenged mice by Western blotting (representative blots are shown).

\section{RESULTS}

\section{Impaired MTA degradation in the liver of LPS-challenged mice}

To evaluate MTA metabolism under oxidative stress, SAM, SAH and MTA levels were measured in the liver of LPS-treated mice, a well-known condition inducing a redox imbalance in hepatic cells. As previously shown [36], the inflammatory reaction associated with LPS administration induced a $50 \%$ reduction of hepatic SAM and SAH. However, the MTA concentration was 2.5-fold higher than that measured in control livers (Figure 1A). No change in MTAP protein levels was observed upon LPS administration as assessed by Western blot analysis (Figure 1B). In agreement with previous studies [37], HO-1 expression was increased in response to the oxidative stress associated with the inflammatory reaction (Figure 1B). Since MTAP catalyses the only known MTA catabolic reaction, the increase in hepatic MTA levels in LPStreated mice, even when the concentration of the precursor SAM was diminished, suggests impairment in MTAP activity. In order to further support this idea, MTAP activity was measured in liver extracts from control and treated mice and a $65 \%$ inactivation was observed upon LPS administration (1.52 \pm 0.02 compared with $0.66 \pm 0.08 \mathrm{nmol} \mathrm{MTA} \cdot \mathrm{min}^{-1} \cdot \mathrm{mg}^{-1}$ of protein in controls and challenged livers respectively).

\section{ROS-mediated MTAP inactivation in hepatic cells}

To investigate the effect of ROS on MTAP activity, HepG2 cells were incubated with t-butyl hydroperoxide and the rate of exogenous MTA consumption was determined. As a negative control the experiment was also performed with SK-Hep1 cells, which we have previously shown to lack MTAP expression [19] (Figure 2B). In all cases, the culture medium was deprived of methionine to prevent endogenous MTA synthesis and was supplemented with horse serum to avoid extracellular MTA degradation by the MTAP present in the commonly used bovine serum [38]. MTA was efficiently degraded by HepG2 MTAP activity within the

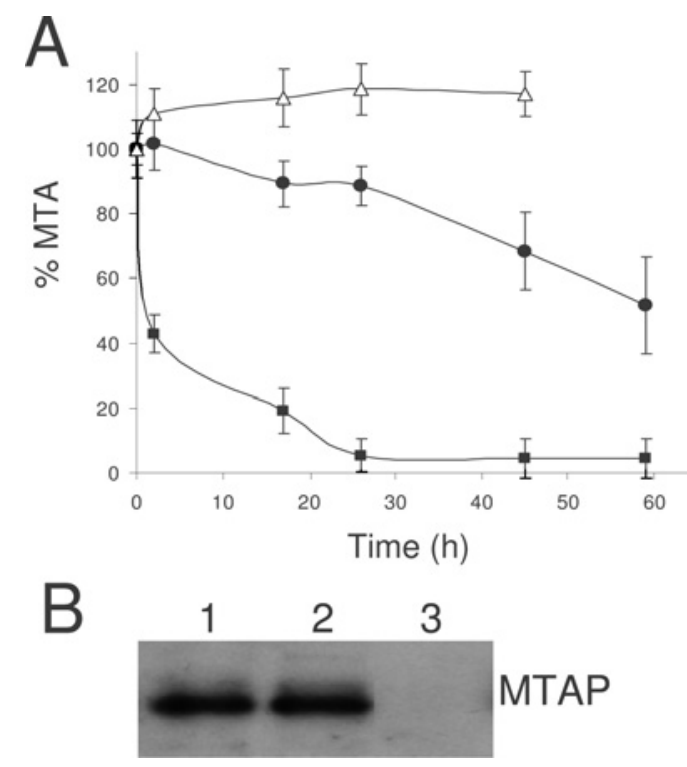

Figure 2 Impairment of MTAP activity in HepG2 cells upon an oxidative challenge

HepG2 cells were incubated in the absence $(\boldsymbol{\square})$ or presence $(\mathbf{O})$ of $1 \mu \mathrm{M} \mathrm{t}$-butyl hydroperoxide, and their capacity to metabolize MTA was measured. As a negative control the MTA-consuming capacity of SK-Hep1 cells $(\Delta)$ lacking MTAP was measured under the same conditions $(\mathbf{A})$. The initial MTA concentration was $16 \mu \mathrm{M}$. The remaining MTA after the different incubation times was measured in the culture medium by HPLC. The MTAP activity calculated for HepG2 cells without t-butyl hydroperoxide was $971.95 \mathrm{pmol} \mathrm{MTA}$ consumed $\cdot \mathrm{mg}^{-1} \cdot \mathrm{min}^{-1}$. (B) MTAP levels were determined by Western blot analysis in HepG2 cells after $48 \mathrm{~h}$ in the absence (lane 1) or presence (lane 2) of $1 \mu \mathrm{M} \mathrm{t-butyl} \mathrm{hydroperoxide} \mathrm{and} \mathrm{in} \mathrm{SK-Hep1} \mathrm{cells} \mathrm{(lane} \mathrm{3).}$ Values are means \pm S.D. of three independent experiments.

first $30 \mathrm{~h}$ of incubation. As expected, the levels of MTA in the culture medium remained unchanged in the presence of SK-Hep1 cells. Induction of oxidative stress with t-butyl hydroperoxide significantly reduced the capacity of HepG2 cells to metabolize the supplemented MTA (only $30 \%$ of the initial MTA was degraded under these conditions), probably resulting from the inactivation of the constitutive MTAP (Figure 2A). The steadystate levels of MTAP protein remained unchanged upon t-butyl hydroperoxide exposure (Figure $2 \mathrm{~B}$ ). These results suggest that cellular MTAP is inactivated by ROS.

\section{$\mathrm{H}_{2} \mathrm{O}_{2}$-induced MTAP inactivation}

The activity of purified MTAP was measured before and after digestion with enterokinase to determine the effect of the $\mathrm{N}$ terminal tag. Only preparations with more than $95 \%$ purity were used for subsequent experiments. Digestion with enterokinase removed the N-terminal tag and resulted in the expected $32 \mathrm{kDa}$ subunits as assessed by SDS/PAGE. Both tagged and digested enzymes had similar MTA-degrading rates of 57.6 and $398 \mathrm{nmol}$. $\mathrm{min}^{-1} \cdot \mathrm{mg}^{-1}$ when the assay was performed with 15 and $200 \mu \mathrm{M}$ MTA respectively (results not shown). Since no apparent change of activity was associated with the $\mathrm{N}$-terminal tag, all the experiments were carried out using the His-tagged recombinant proteins. The putative effect of ROS on MTAP activity was studied by pre-incubation of the enzyme with $\mathrm{H}_{2} \mathrm{O}_{2}$. Independently of whether the protein was processed with enterokinase or not, a $60 \%$ decrease of the enzymatic activity was measured after oxidation and the inactivation was reversed when the activity assay was performed in the presence of reducing agents (Supplementary Figure at http://www.BiochemJ.org/bj/411/bj4110457add.htm). 
Table $1 \quad V_{\max }$ and $\boldsymbol{K}_{\mathrm{m}}$ values for reduced and oxidized MTAP

\begin{tabular}{lcc}
\hline & $V_{\max }\left(\mathrm{nmol}\right.$ MTA consumed $\left.\cdot \mathrm{min}^{-1} \cdot \mathrm{mg}^{-1}\right)$ & $K_{\mathrm{m}}(\mu \mathrm{M})$ \\
\hline MTAP & $433 \pm 29.37$ & $32.77 \pm 9.42$ \\
MTAP $+100 \mu \mathrm{M} \mathrm{H}_{2} \mathrm{O}_{2}$ & $271.9 \pm 22.45$ & $24.93 \pm 9.78$ \\
MTAP $+500 \mu \mathrm{M} \mathrm{H}_{2} \mathrm{O}_{2}$ & $168.97 \pm 8.34$ & $37.18 \pm 7.42$ \\
\end{tabular}

The hydrodynamic properties of the recombinant MTAP purified from $E$. coli extracts were analysed by size-exclusion chromatography. The elution volume of recombinant MTAP was $13.28 \mathrm{ml}$, which is compatible with a molecular mass of $108 \mathrm{kDa}$ according to the elution profile of standard proteins. This result indicates that the purified MTAP is a trimer of tagged subunits. Since the elution volume of the protein remained unchanged upon incubation with $\mathrm{H}_{2} \mathrm{O}_{2}$ (13.22 ml), oxidation-associated changes of the trimeric structure of MTAP were ruled out (results not shown). To get an insight into the mechanism of $\mathrm{H}_{2} \mathrm{O}_{2}$-mediated inactivation of MTAP, kinetic experiments were performed. $V_{\max }$ was reduced from $433 \pm 29$ to $169 \pm 8 \mathrm{nmol} \mathrm{MTA} \mathrm{consumed} \cdot \mathrm{min}^{-1} \cdot \mathrm{mg}^{-1}$ in the absence or presence of $500 \mu \mathrm{M} \mathrm{H}_{2} \mathrm{O}_{2}$ respectively (Table 1 and Supplementary Figure 1). The estimated $K_{\mathrm{m}}$ for MTA (approx. $30 \mu \mathrm{M}$ ) remained unchanged upon oxidation (Table 1 and Supplementary Figure 1), suggesting that the loss of activity might result from impairment of the catalytic mechanism more than from impeded MTA binding to the active site of the enzyme. Therefore these results suggest that $\mathrm{H}_{2} \mathrm{O}_{2}$ is a non-competitive inhibitor with an estimated $\mathrm{IC}_{50}$ of approx. $300 \mu \mathrm{M}$.

\section{Identification of target cysteine residues involved in the impairment of MTAP activity by ROS}

In order to elucidate the participation of cysteine residues on MTAP inactivation by oxidation and to identify the targeted cysteine residue(s), nine mutant MTAP proteins in which a single cysteine residue was replaced by a serine residue were obtained and their susceptibility to inactivation by $\mathrm{H}_{2} \mathrm{O}_{2}$ was analysed. Mutants were expressed and purified from $E$. coli extracts and the purity of the corresponding proteins was always more than $95 \%$ in all preparations used. Replacement of cysteine by serine had no effect on the enzymatic activity of MTAP mutants. Similarly to the WT enzyme, the activity measured at a saturating concentration of MTA was close to $396 \mathrm{nmol} \mathrm{MTA} \mathrm{consumed} \cdot \mathrm{min}^{-1} \cdot \mathrm{mg}^{-1}$ in all cases (Figure 3A). Incubation with $500 \mu \mathrm{M} \mathrm{H}_{2} \mathrm{O}_{2}$ reduced the activity of WT and mutant proteins to approx. $132 \mathrm{nmol}$ MTA consumed $\cdot \mathrm{min}^{-1} \cdot \mathrm{mg}^{-1}$ with the exception of C136S and C223S MTAP species that remained fully active after oxidation (Figure 3A). These results suggest that the oxidation of both $\mathrm{Cys}^{136}$ and $\mathrm{Cys}^{223}$ is required to mediate MTAP inactivation. The loss of sensitivity to inactivation by ROS of C136S and C223S mutants was also investigated in hepatic cells. In order to do this, stably transfected SK-Hep1 cells expressing these two MTAP mutants were challenged with $10 \mu \mathrm{M}$ t-butyl hydroperoxide and the consumption of extracellular MTA was measured after $30 \mathrm{~h}$. MTAP mutant protein levels (as determined by Western blot analysis) and the capacity of MTA degradation by transfected SK-Hep1 cells were similar to those observed in HepG2 cells that express the endogenous enzyme (800-1000 pmol MTA consumed $\left.\cdot \mathrm{mg}^{-1} \cdot \mathrm{min}^{-1}\right)$. SK-Hep1 cells expressing either of the two mutants were not sensitive to t-butyl hydroperoxide and their MTA-metabolizing activity remained unchanged after exposure to the oxidant (Figure 3B), further supporting the central role of $\mathrm{Cys}^{136}$ and $\mathrm{Cys}^{223}$ in mediating MTAP inactivation by ROS. In contrast, SK-Hep1 cells transfected with a vector expressing WT

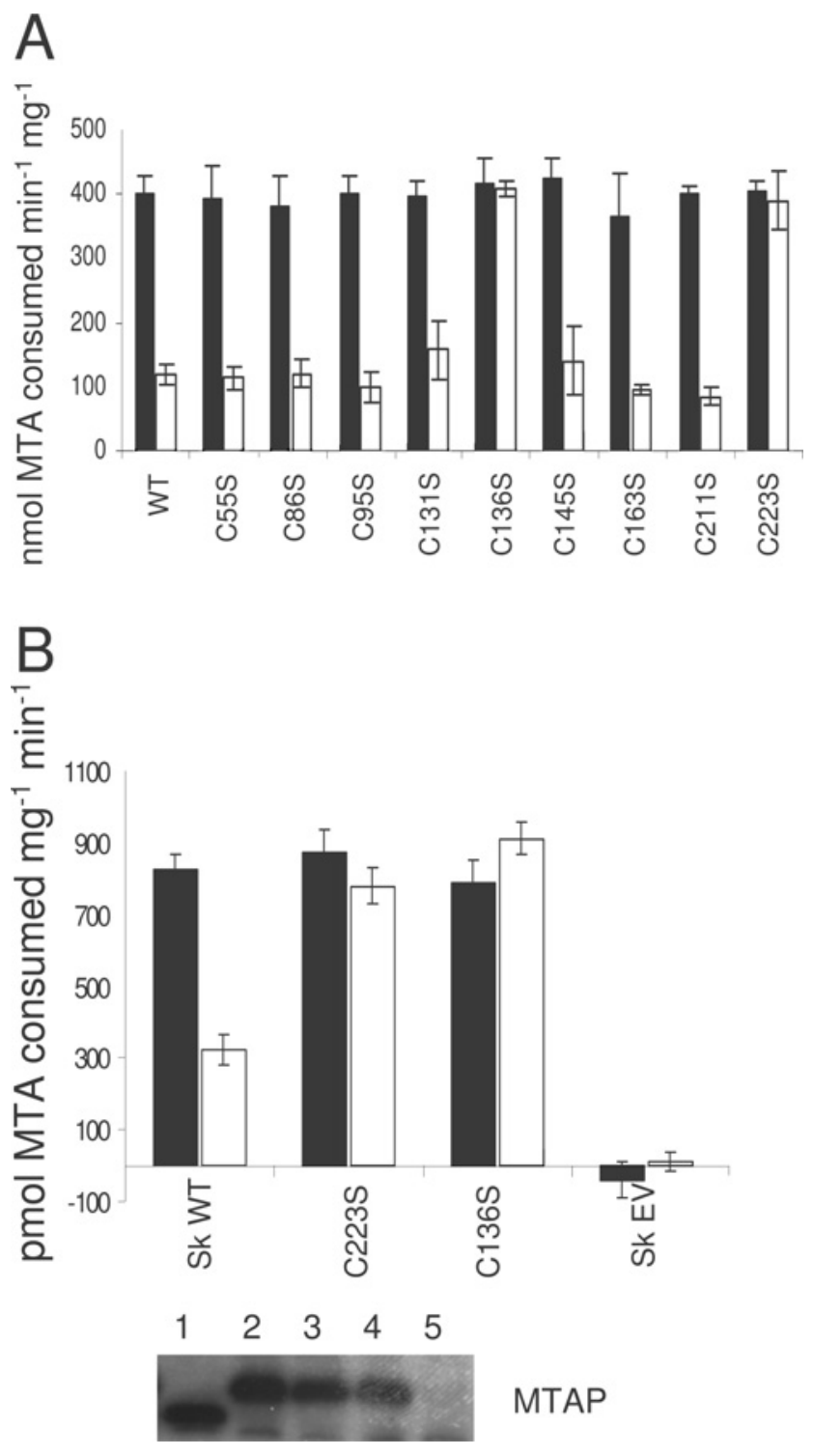

Figure 3 Identification of cysteine residues mediating MTAP inactivation by ROS

(A) The activity of WT and mutant MTAP proteins was measured in the absence (solid bars) or presence (open bars) of $500 \mu \mathrm{M} \mathrm{H}_{2} \mathrm{O}_{2}$. The MTAP concentration was $1 \mu \mathrm{M}$ in all cases and the initial and final amount of MTA was measured by HPLC. (B) The MTA metabolizing rate was measured in SK-Hep1 cells stably transfected with an empty vector (SK-EV) or expressing human WT (SK-WT), C136S or C223S MTAP mutants in the absence (solid bars) or presence (open bars) of $10 \mu \mathrm{M} \mathrm{t-butyl} \mathrm{hydroperoxide.} \mathrm{MTA} \mathrm{was} \mathrm{added} \mathrm{to} \mathrm{the} \mathrm{culture} \mathrm{medium} \mathrm{at} \mathrm{an} \mathrm{initial}$ concentration of $16 \mu \mathrm{M}$. The MTA content in the culture medium was measured by HPLC. The Western blot shows MTAP levels in HepG2 (lane 1) and SK-Hep1 cells expressing WT MTAP (lane 2), C136S (lane 3), C223S (lane 4) or transfected with an empty vector (lane 5). Values are means \pm S.D. of three independent experiments.

MTAP showed the expected decrease (approx. 60\%) of MTA consumption upon exposure to t-butyl hydroperoxide.

\section{Identification of cysteine-SH oxidation derivatives}

To characterize the thiol-oxidation derivatives leading to MTAP inactivation we first measured the number of accessible cysteine residues remaining upon incubation with $\mathrm{H}_{2} \mathrm{O}_{2}$. The protein was oxidized and then denatured in $6 \mathrm{M}$ guanidinium chloride to ensure titration of all free cysteine residues with DTNB. 

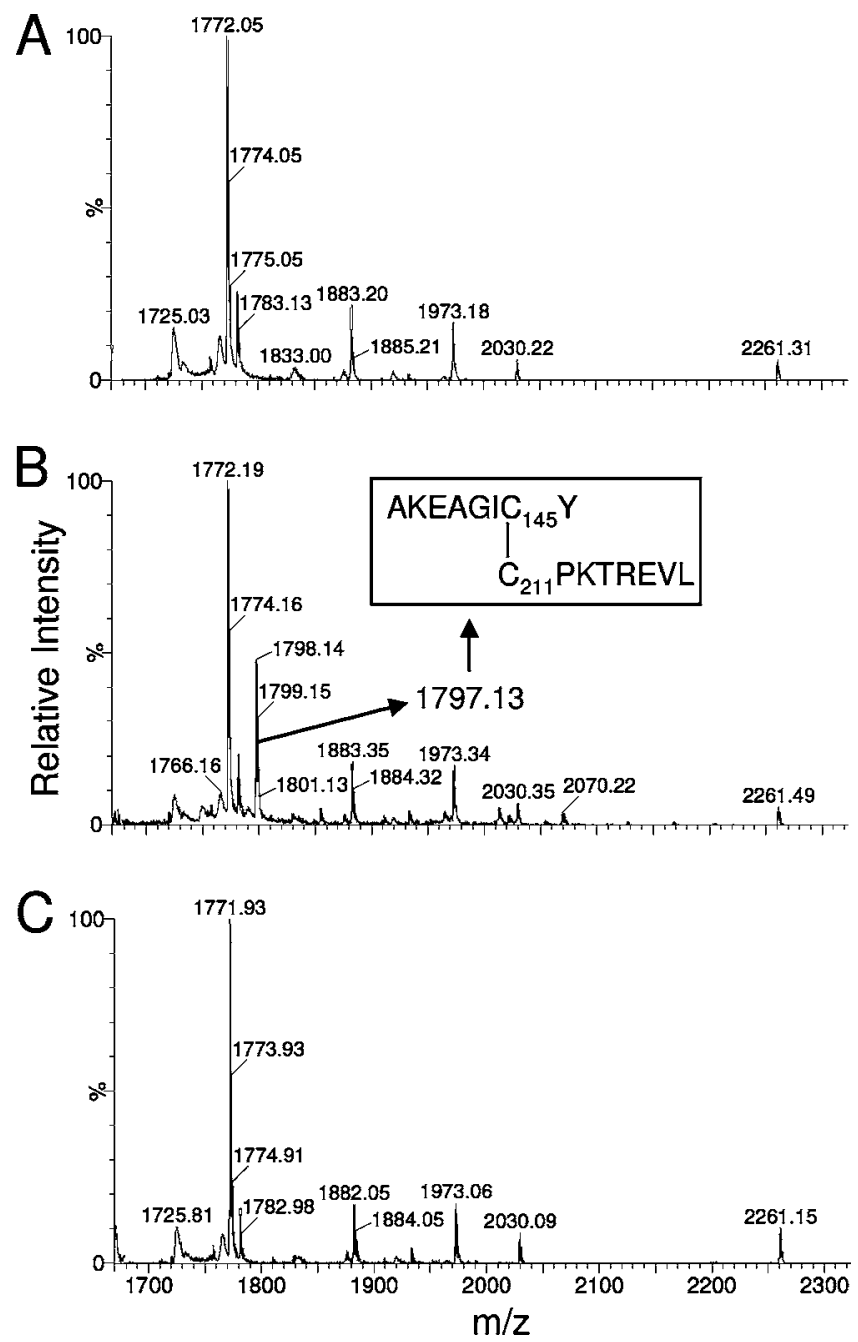

\section{Figure 4 MS detection of Cys ${ }^{145}$-S-S-Cys ${ }^{211}$ disulfide interaction}

MALDI-TOF MS spectra of tryptic digests from (A) DTT treated, (B) $\mathrm{H}_{2} \mathrm{O}_{2}$ treated or $(\mathbf{C}) \mathrm{H}_{2} \mathrm{O}_{2}$ and then DTT treated WT MTAP were obtained. $\mathrm{H}_{2} \mathrm{O}_{2}$ was removed before chymotrypsinolysis to avoid peptide cross-linking by disulfide interactions during digestion. The insert in $(\mathbf{B})$ indicates the sequence of the two MTAP peptides containing Cys ${ }^{145}$ and Cys ${ }^{211}$ whose interaction is consistent with the $\mathrm{H}_{2} \mathrm{O}_{2}$-associated detection of a 1797.13 Da ion.

This procedure allowed detection of ten cysteine residues in the reduced protein, which is compatible with the presence of nine cysteine residues in the MTAP sequence and one additional residue provided by the $\mathrm{N}$-terminal tag. Incubation with $\mathrm{H}_{2} \mathrm{O}_{2}$ restricted the access of the thiol-reacting reagent to four cysteine residues independently of the time of exposure to the oxidant, suggesting the oxidation of six cysteine residues as was further supported by the recovery of reactivity of all ten cysteine residues with DTT. This evidence indicates oxidation of cysteine residues additionally to those responsible for MTAP inactivation by ROS. MS analyses were then performed on tryptic and chymotryptic digests from reduced and $\mathrm{H}_{2} \mathrm{O}_{2}$-treated MTAP aiming to identify cysteine residues involved in a putative disulfide bonding. Ion assignment from MALDI-TOF spectra allowed more than $60 \%$ coverage of the MTAP sequence in all cases. Interestingly, a 1797.13 Da ion was specifically detected on peptide fingerprints from $\mathrm{H}_{2} \mathrm{O}_{2}$-oxidized MTAP and the presence of this peptide species was prevented when oxidation was reversed with DTT (Figure 4). The differential ion might result from the interaction between $\mathrm{Cys}^{145}$ and $\mathrm{Cys}^{211}$ leading to the association

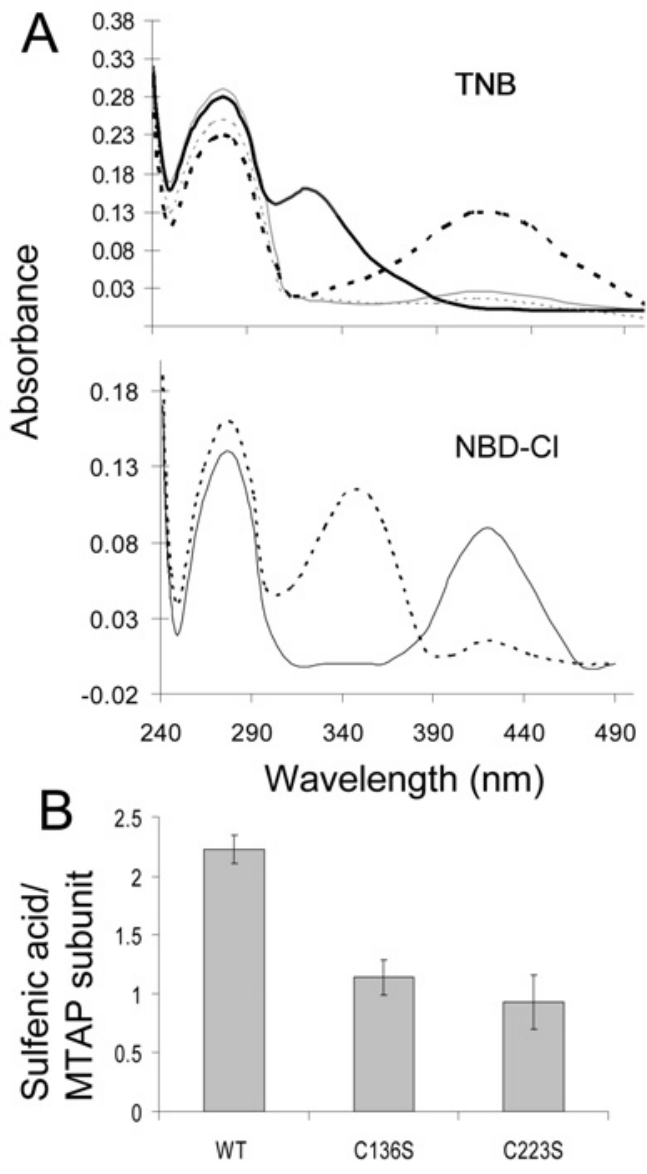

Figure 5 Oxidation of $\mathrm{Cys}^{136}$ and $\mathrm{Cys}^{233}$ to sulfenic acid

Sulfenic acid derivatives were detected by incubation of reduced or oxidized native MTAP with TNB or NBD-CI (A). For TNB experiments, control (dashed line) or $\mathrm{H}_{2} \mathrm{O}_{2}$ - (solid line), DTT(dotted line) and $\mathrm{H}_{2} \mathrm{O}_{2}$ and then DTT- (dashed and dotted line) treated MTAP were assayed. For NBD-Cl, control (solid line) or $\mathrm{H}_{2} \mathrm{O}_{2}$ (dashed line) conditions were analysed. The number of sulfenic derivatives per MTAP subunit was estimated by titration with TNB (B). Values are means \pm S.D. of three independent experiments.

of the corresponding chymotryptic peptides as suggested by the experimental molecular mass which is $2 \mathrm{Da}$ less than that theoretically predicted from the sequence, in agreement with a disulfide-bridged dipeptide. Since no additional cysteine derivatives were identified, the oxidation state of $\mathrm{Cys}^{136}$ and $\mathrm{Cys}^{223}$, responsible for MTAP inactivation, remained unclear. Oxidation to sulfenic acid was then explored using TNB or, alternatively, NBD-Cl. Control MTAP yielded negative results when incubated with either sulfenic-specific reagents. However, after exposure to $\mathrm{H}_{2} \mathrm{O}_{2}$, sulfenic acids were observed independently of the detection method used and were not detectable if the oxidized and modified enzyme were treated with DTT. TNB reagent allowed titration of two sulfenic groups per MTAP subunit (Figure 5). Substitution of $\mathrm{Cys}^{136}$ or $\mathrm{Cys}^{223}$ by serine resulted in MTAP variants that contained only one sulfenic acid after oxidation (Figure 5). These results indicate that $\mathrm{H}_{2} \mathrm{O}_{2}$-induced MTAP inactivation results from oxidation of $\mathrm{Cys}^{136}$ and $\mathrm{Cys}^{223}$ to sulfenic acid. A reduction of the $412 \mathrm{~nm}$ signal was observed if oxidation was prolonged over $30 \mathrm{~min}$, suggesting that the sulfenic groups might evolve to more stable derivatives (Supplementary Figure 2 at http://www.BiochemJ.org/bj/411/bj4110457add.htm). 


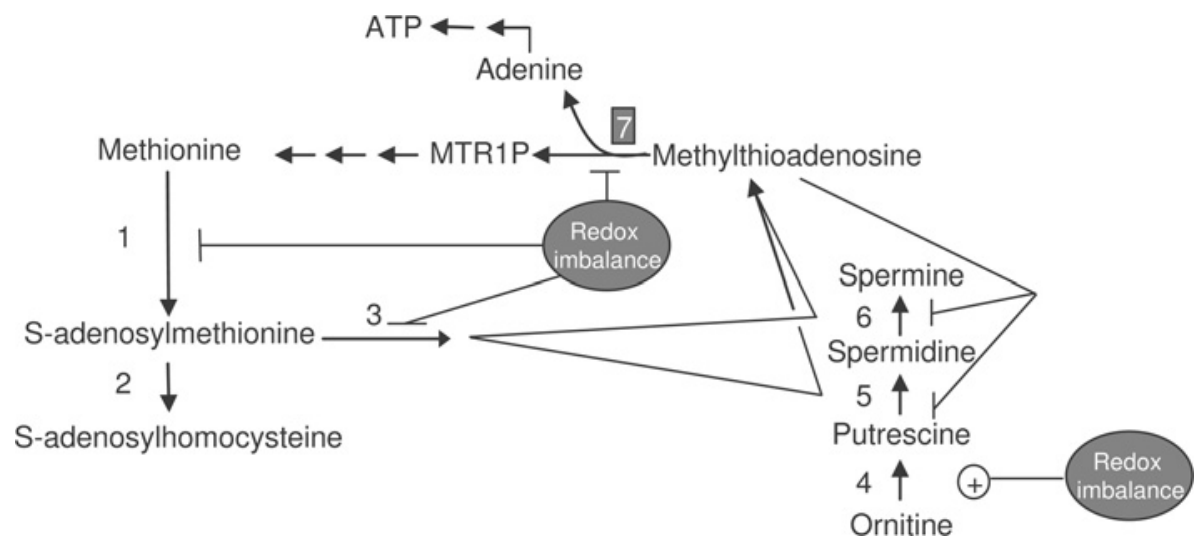

Figure 6 Schematic representation of MTA metabolism

Checkpoints modulated by redox imbalance are indicated. (1) Methionine adenosyltransferase, (2) methyl transferases, (3) S-adenosylmethionine decarboxylase, (4) ornithine decarboxylase, (5) spermidine synthase, (6) spermine synthase and (7) 5'-methylthioadeosine phosphorylase.

\section{DISCUSSION}

The participation of MTA in essential metabolic and signalling pathways suggests that the regulation of MTAP activity might be important in facilitating cellular adaptation to physiological or pathological conditions. The liver parenchyma is one of the normal human tissue types where MTAP gene expression is higher [39]. It has been demonstrated that methionine metabolism must be precisely tuned to maintain normal liver function and that impairment of this pathway correlates with hepatocyte dedifferentiation and proliferation leading to the progression of liver diseases [4,40]. Consistent with the central role of MTA in the cell, a conservative mechanism based on a co-ordinated regulation of MAT (methionine adenosyltransferase), the enzyme catalysing the synthesis of the precursor SAM, and MTAP might prevent a deleterious MTA decrease in hepatocytes (Figure 6). First, the oxidative stress resulting from mild and transient liver damage inactivates MAT perhaps providing an adaptive response that allows hepatocyte survival [41]. Down-regulation of MAT might be correlated with reversible inactivation of MTAP, as has been shown in the present study, to compensate the impaired SAM synthesis leading to maintenance of cellular MTA. Cellular antioxidant defences might reactivate MAT [42] and MTAP returning methionine catabolism and salvage pathways to their normal steady-state. However, the maintenance of the diseased condition results in a persistent impairment of liver MAT [43] and MTAP [19] gene expression through epigenetic mechanisms. In light of these observations it might by hypothesized that impairment of SAM synthesis might be compensated, at least partially, by inactivation of MTAP leading to maintenance of MTA levels that may be critical for cellular stability. The idea of a co-ordinated regulation of MTA metabolism by the redox state of the cell might be further reinforced by results indicating the inactivation of SAM decarboxylase by reactive species [44]. Interestingly, it has been reported that the hepatic levels of putrescine are increased in murine liver upon treatment with LPS resulting from up-regulation of ornithine decarboxylase. However, the increment of putrescine did not promote a parallel increase in spermidine and spermine (Figure 6) [45]. Our results might explain these observations since MTA, which accumulates in the liver of LPS-treated mice as a result of MTAP inactivation, inhibits spermine and spermidine synthases $[1,6]$.

Protein oxidation is a common regulatory mechanism of metabolic and signalling pathways [46]. Native MTAP is a homo- trimer with active sites composed entirely of residues of the same subunit with the exception of $\mathrm{His}^{137}$ and $\mathrm{Leu}^{279}$ that are provided by the neighbouring monomer [13]. The loss of MTAP activity upon exposure to $\mathrm{H}_{2} \mathrm{O}_{2}$ is a reversible process that results from the specific oxidation of cysteine residues 136 and 223 as was demonstrated by using the purified enzyme as well as cellular systems whose MTA consumption capacity was severely impaired after an oxidative challenge. These two cysteine residues are conserved in mammalian MTAPs and in the Drosophila melanogaster orthologue but are not present in other MTAP sequences, explaining the lack of cysteine-mediated redox regulation reported in different archaea species [11]. No structural or functional evidence support a direct participation of cysteine residues in MTA binding or in the catalytic mechanism of MTAP, consistent with our finding that the activity of the enzyme remains as in the WT protein when cysteine residues were replaced by serine. However, specific oxidation of $\mathrm{Cys}^{136}$ and $\mathrm{Cys}^{223}$ resulted in a reduced $V_{\max }$ while the $K_{\mathrm{m}}$ of the enzyme remained unchanged, suggesting that the binding of MTA to the active site of MTAP is not modified in the oxidized form. Interestingly, $\mathrm{Cys}^{223}$ is located on a flexible loop over the active-site cleft of MTAP connecting $\beta$-strand 11 with $\alpha$-helix 5 and is close to $\mathrm{Asp}^{220}$ and $\mathrm{Asp}^{222}$ which participate in the catalytic process and $\mathrm{Cys}^{136}$ is adjacent to His $^{137}$ that integrates the MTA-binding pocket of the neighbouring subunit [13]. Moreover, non-conservative substitution of $\mathrm{Cys}^{223}$ by tyrosine resulted in an inactive MTAP mutant [47]. Therefore it is tempting to speculate that the oxidation of $\mathrm{Cys}^{136}$ and $\mathrm{Cys}^{223}$ might alter the microenvironment of these catalytic residues modifying their chemical reactivity and consequently the activity of the enzyme.

Oxidation of the two cysteine residues is required to promote MTAP inactivation as indicated by the loss of sensitivity of $\mathrm{C} 136 \mathrm{~S}$ and $\mathrm{C} 233 \mathrm{~S}$ mutants to inactivation by $\mathrm{H}_{2} \mathrm{O}_{2}$. The idea of a disulfide interaction between these residues arises as a probable explanation to the co-ordinated effect of the two oxidation events on MTAP inactivation. However, the distances separating the corresponding sulphur atoms of $\mathrm{Cys}^{136}$ and $\mathrm{Cys}^{233}$ from adjacent subunits are $15.77 \AA(1 \AA=0.1 \mathrm{~nm})$ and $35.54 \AA$ in the same MTAP monomer [13], too far away to allow prediction of their interaction without assuming conformational rearrangements that to our knowledge have not yet been demonstrated. Consistently, the only disulfide bond clearly identified upon oxidation with $\mathrm{H}_{2} \mathrm{O}_{2}$ involved Cys ${ }^{145}$ and $\mathrm{Cys}^{211}$ as expected from the $3.63 \AA$ separating their thiol groups. Additionally DTNB titration data 
indicate that six cysteine residues from the MTAP monomer become oxidized upon incubation with $\mathrm{H}_{2} \mathrm{O}_{2}$ and therefore two cysteine residues supplementary to $\mathrm{Cys}^{136}, \mathrm{Cys}^{145}, \mathrm{Cys}^{211}$ and $\mathrm{Cys}^{223}$ may undergo oxidation.

Incubation of MTAP with $\mathrm{H}_{2} \mathrm{O}_{2}$ led to oxidation of $\mathrm{Cys}^{136}$ and $\mathrm{Cys}^{223}$ to reversible sulfenic acid. Longer exposures of MTAP to $\mathrm{H}_{2} \mathrm{O}_{2}$ to those reported in the present study resulted in oxidized forms that displayed hydrodynamic volumes larger than those expected for the monomer when analysed by size-exclusion chromatography under denaturing conditions (Supplementary Figure 2). This observation may suggest a reversible intersubunit interaction that should involve $\mathrm{Cys}^{136}$ and $\mathrm{Cys}^{223}$ since the effect was reversed by reducing agents, and mutants lacking these residues failed to accumulate the putatively cross-linked intermediate. Since no disulfide interactions additional to $\mathrm{Cys}^{145}$ S-S-Cys ${ }^{211}$ were detected, our observations may be explained alternatively assuming the stabilization of $\mathrm{Cys}^{136}$ and/or Cys ${ }^{223}$ sulfenic derivatives through reaction with residues located in the adjacent monomer leading to the formation of reversible intermediates such as sulfenyl amides $[48,49]$. This notion might find further support on the time-dependent reduction of sulfenic content per protein subunit observed after oxidation periods longer than $30 \mathrm{~min}$, suggesting their stabilization to derivatives that were recycled back to reduced thiols with reducing agents (Supplementary Figure 2). Detailed structural studies are required to demonstrate these hypotheses and to fully elucidate the ROSinduced oxidation intermediates of MTAP.

In summary, the results of the present study support the loss of MTAP activity in the liver of LPS-challenged mice as well as in HepG2 cells exposed to t-butyl hydroperoxide. MTAP activity is regulated by mechanisms involving the specific and reversible oxidation of cysteine residues $\mathrm{Cys}^{136}$ and $\mathrm{Cys}^{233}$ to sulfenic acid that may be further stabilized to a sulfenyl amide intermediate. Additional oxidation events result in disulfide bonding of Cys ${ }^{145}$ and $\mathrm{Cys}^{211}$ thiols, although this modification has no impact on the enzymatic activity of MTAP. In the liver this regulatory mechanism might provide means to maintain intracellular MTA levels under stress conditions such as those imposed by inflammatory reactions ensuring hepatocyte viability.

The technical assistance of Goretti Azparren, Sonia Beaumont, and María I. Mora is acknowledged. This work was supported by: the agreement between FIMA and the 'UTE project CIMA'; grants Plan Nacional I + D + I 2004-03538 and 2004-01855 from Ministerio de Educación y Ciencia to M.A. A. and F.J.C.; grant ROI AA-12677 from the National Institute on Alcohol Abuse and Alcoholism to, M. A. A.; grant R01 AT1576 from the National Center for Complementary and Alternative Medicine to M.A.A. and F.J.C.; grant R01 AA013847 from the National Center for Complementary and Alternative Medicine to F.J.C.; grant STREP FP6-2004-LIFESCIHEALTH-5 018649 from the $6^{\text {th }}$ framework programm of the UE to F.J.C. ISCIII-RETIC RD06/0020 to M. A. A. and F.J.C. Grant FIS CP04/00123 from Ministerio de Sanidad y Consumo to M. S. and M. A. A. M. U. L. is supported by a Juan de la Cierva contract from the Ministerio de Educación y Ciencia, Spain. This laboratory is member of the National Institute of Proteomics Facilities, ProteoRed.

\section{REFERENCES}

1 Pegg, A. E. (1988) Polyamine metabolism and its importance in neoplastic growth and a target for chemotherapy. Cancer Res. 48, 759-774

2 Wu, S. E., Huskey, W. P., Borchardt, R. T. and Schowen, R. L. (1983) Chiral instability at sulfur of S-adenosylmethionine. Biochemistry 22, 2828-2832

3 Williams-Ashman, H. G., Seidenfeld, J. and Galletti, P. (1982) Trends in the biochemical pharmacology of 5'-deoxy-5'-methylthioadenosine. Biochem. Pharmacol. 31, 277-288

4 Mato, J. M., Corrales, F. J., Lu, S. C. and Avila, M. A. (2002) S-Adenosylmethionine: a control switch that regulates liver function. FASEB J. 16, 15-26

5 Hevia, H., Varela-Rey, M., Corrales, F. J., Berasain, C., Martinez-Chantar, M. L., Latasa, M. U., Lu, S. C., Mato, J. M., Garcia-Trevijano, E. R. and Avila, M. A. (2004) $5^{\prime}$-methylthioadenosine modulates the inflammatory response to endotoxin in mice and in rat hepatocytes. Hepatology 39, 1088-1098
6 Pascale, R. M., Simile, M. M., De Miglio, M. R. and Feo, F. (2002) Chemoprevention of hepatocarcinogenesis: S-adenosyl-L-methionine. Alcohol 27, 193-198

7 Maher, P. A. (1993) Inhibition of the tyrosine kinase activity of the fibroblast growth factor receptor by the methyltransferase inhibitor $5^{\prime}$-methylthioadenosine. J. Biol. Chem. 268, 4244-4249

8 Avila, M. A., Garcia-Trevijano, E. R., Lu, S. C., Corrales, F. J. and Mato, J. M. (2004) Methylthioadenosine. Int. J. Biochem. Cell Biol. 36, 2125-2130

9 Moreno, B., Hevia, H., Santamaria, M., Sepulcre, J., Munoz, J., Garcia-Trevijano, E. R., Berasain, C., Corrales, F. J., Avila, M. A. and Villoslada, P. (2006) Methylthioadenosine reverses brain autoimmune disease. Ann. Neurol. 60, 323-334

10 Pegg, A. E. and Williams-Ashman, H. G. (1969) Phosphate-stimulated breakdown of 5'-methylthioadenosine by rat ventral prostate. Biochem. J. 115, 241-247

11 Cacciapuoti, G., Forte, S., Moretti, M. A., Brio, A., Zappia, V. and Porcelli, M. (2005) A novel hyperthermostable $5^{\prime}$-deoxy-5'-methylthioadenosine phosphorylase from the archaeon Sulfolobus solfataricus. FEBS J. 272, 1886-1899

12 Della Ragione, F., Takabayashi, K., Mastropietro, S., Mercurio, C., Oliva, A., Russo, G. L., Della Pietra, V., Borriello, A., Nobori, T., Carson, D. A. and Zappia, V. (1996) Purification and characterization of recombinant human 5 '-methylthioadenosine phosphorylase: definite identification of coding cDNA. Biochem. Biophys. Res. Commun. 223, 514-519

13 Appleby, T. C., Erion, M. D. and Ealick, S. E. (1999) The structure of human $5^{\prime}$-deoxy-5'-methylthioadenosine phosphorylase at $1.7 \AA$ resolution provides insights into substrate binding and catalysis. Structure 7, 629-641

14 Olopade, O. I., Pomykala, H. M., Hagos, F., Sveen, L. W., Espinosa, 3rd, R., Dreyling, M. H., Gursky, S., Stadler, W. M., Le Beau, M. M. and Bohlander, S. K. (1995) Construction of a 2.8-megabase yeast artificial chromosome contig and cloning of the human methylthioadenosine phosphorylase gene from the tumor suppressor region on 9p21. Proc. Natl. Acad. Sci. U.S.A. 92, 6489-6493

15 Kamatani, N. and Carson, D. A. (1981) Dependence of adenine production upon polyamine synthesis in cultured human lymphoblasts. Biochim. Biophys. Acta $\mathbf{6 7 5}$ 344-350

16 Christopher, S. A., Diegelman, P., Porter, C. W. and Kruger, W. D. (2002) Methylthioadenosine phosphorylase, a gene frequently codeleted with p16(cdkN2a/ARF), acts as a tumor suppressor in a breast cancer cell line. Cancer Res. 62, 6639-6644

17 Illei, P. B., Rusch, V. W., Zakowski, M. F. and Ladanyi, M. (2003) Homozygous deletion of CDKN2A and codeletion of the methylthioadenosine phosphorylase gene in the majority of pleural mesotheliomas. Clin. Cancer Res. 9, 2108-2113

18 Behrmann, I., Wallner, S., Komyod, W., Heinrich, P. C., Schuierer, M., Buettner, R. and Bosserhoff, A. K. (2003) Characterization of methylthioadenosin phosphorylase (MTAP) expression in malignant melanoma. Am. J. Pathol. 163, 683-690

19 Berasain, C., Hevia, H., Fernandez-Irigoyen, J., Larrea, E., Caballeria, J., Mato, J. M., Prieto, J., Corrales, F. J., Garcia-Trevijano, E. R. and Avila, M. A. (2004) Methylthioadenosine phosphorylase gene expression is impaired in human liver cirrhosis and hepatocarcinoma. Biochim. Biophys. Acta 1690, 276-284

20 Hellerbrand, C., Muhlbauer, M., Wallner, S., Schuierer, M., Behrmann, I., Bataille, F., Weiss, T., Scholmerich, J. and Bosserhoff, A. K. (2006) Promoter-hypermethylation is causing functional relevant downregulation of methylthioadenosine phosphorylase (MTAP) expression in hepatocellular carcinoma. Carcinogenesis 27, 64-72

21 Kadariya, Y., Nakatani, K., Nishioka, J., Fujikawa, T., Kruger, W. D. and Nobori, T. (2005) Regulation of human methylthioadenosine phosphorylase gene by the CBF (CCAAT binding factor)/NF-Y (nuclear factor-Y). Biochem. J. 387, 175-183

22 Beausoleil, S. A., Jedrychowski, M., Schwartz, D., Elias, J. E., Villen, J., Li, J., Cohn, M. A., Cantley, L. C. and Gygi, S. P. (2004) Large-scale characterization of HeLa cell nuclear phosphoproteins. Proc. Natl. Acad. Sci. U.S.A. 101, 12130-12135

23 Della Ragione, F., Carteni-Farina, M., Gragnaniello, V., Schettino, M. I. and Zappia, V. (1986) Purification and characterization of $5^{\prime}$-deoxy-5'-methylthioadenosine phosphorylase from human placenta. J. Biol. Chem. 261, 12324-12329

24 Zhang, Y., Porcelli, M., Cacciapuoti, G. and Ealick, S. E. (2006) The crystal structure of 5'-deoxy-5'-methylthioadenosine phosphorylase II from Sulfolobus solfataricus, a thermophilic enzyme stabilized by intramolecular disulfide bonds. J. Mol. Biol. 357, 252-262

25 Perez-Mato, I., Castro, C., Ruiz, F. A., Corrales, F. J. and Mato, J. M. (1999) Methionine adenosyltransferase S-nitrosylation is regulated by the basic and acidic amino acids surrounding the target thiol. J. Biol. Chem. 274, 17075-17079

26 Velasco, J. A., Avila, M. A. and Notario, V. (1999) The product of the cph oncogene is a truncated, nucleotide-binding protein that enhances cellular survival to stress. Oncogene 18, 689-701

27 Chomczynski, P. and Sacchi, N. (1987) Single-step method of RNA isolation by acid guanidinium thiocyanate-phenol-chloroform extraction. Anal. Biochem. 162, 156-159

28 Mingorance, J., Alvarez, L., Sanchez-Gongora, E., Mato, J. M. and Pajares, M. A. (1996) Site-directed mutagenesis of rat liver S-adenosylmethionine synthetase. Identification of a cysteine residue critical for the oligomeric state. Biochem. J. 315, 761-766 
29 Laemmli, U. K. (1970) Cleavage of structural proteins during the assembly of the head of bacteriophage T4. Nature 227, 680-685

30 Bradford, M. M. (1976) A rapid and sensitive method for the quantitation of microgram quantities of protein utilizing the principle of protein-dye binding. Anal. Biochem. 72 , 248-254

31 Singh, V., Shi, W., Evans, G. B., Tyler, P. C., Furneaux, R. H., Almo, S. C. and Schramm, V. L. (2004) Picomolar transition state analogue inhibitors of human 5 '-methylthioadenosine phosphorylase and X-ray structure with MT-immucillin-A. Biochemistry 43, 9-18

32 Cavallini, D., Graziani, M. T. and Dupre, S. (1966) Determination of disulphide groups in proteins. Nature 212, 294-295

33 Ellman, G. L. (1959) Tissue sulfhydryl groups. Arch. Biochem. Biophys. 82, 70-77

34 Poole, L. B. and Claiborne, A. (1989) The non-flavin redox center of the streptococcal NADH peroxidase. II. Evidence for a stabilized cysteine-sulfenic acid. J. Biol. Chem. 264, 12330-12338

35 Ellis, H. R. and Poole, L. B. (1997) Novel application of 7-chloro-4-nitrobenzo-2-oxa-1,3-diazole to identify cysteine sulfenic acid in the AhpC component of alkyl hydroperoxide reductase. Biochemistry 36, 15013-15018

36 Payabvash, S., Ghahremani, M. H., Goliaei, A., Mandegary, A., Shafaroodi, H., Amanlou, M. and Dehpour, A. R. (2006) Nitric oxide modulates glutathione synthesis during endotoxemia. Free Radical Biol. Med. 41, 1817-1828

37 Schock, B. C., Van der Vliet, A., Corbacho, A. M., Leonard, S. W., Finkelstein, E., Valacchi, G., Obermueller-Jevic, U., Cross, C. E. and Traber, M. G. (2004) Enhanced inflammatory responses in $\alpha$-tocopherol transfer protein null mice. Arch. Biochem. Biophys. 423, 162-169

38 Riscoe, M. K. and Ferro, A. J. (1984) 5-Methylthioribose. Its effects and function in mammalian cells. J. Biol. Chem. 259, 5465-5471

39 Nobori, T., Takabayashi, K., Tran, P., Orvis, L., Batova, A., Yu, A. L. and Carson, D. A. (1996) Genomic cloning of methylthioadenosine phosphorylase: a purine metabolic enzyme deficient in multiple different cancers. Proc. Natl. Acad. Sci. U.S.A. 93 $6203-6208$

Received 16 November 2007/30 January 2008; accepted 31 January 2008

Published as BJ Immediate Publication 31 January 2008, doi:10.1042/BJ20071569
40 Calvisi, D. F., Simile, M. M., Ladu, S., Pellegrino, R., De Murtas, V., Pinna, F., Tomasi, M. L., Frau, M., Virdis, P., De Miglio, M. R. et al. (2007) Altered methionine metabolism and global DNA methylation in liver cancer: Relationship with genomic instability and prognosis. Int. J. Cancer. 121, 2410-2420

41 Sanchez-Gongora, E., Pastorino, J. G., Alvarez, L., Pajares, M. A., Garcia, C., Vina, J. R., Mato, J. M. and Farber, J. L. (1996) Increased sensitivity to oxidative injury in chinese hamster ovary cells stably transfected with rat liver S-adenosylmethionine synthetase cDNA. Biochem. J. 319, 767-773

42 Corrales, F. J., Ruiz, F. and Mato, J. M. (1999) In vivo regulation by glutathione of methionine adenosyltransferase S-nitrosylation in rat liver. J. Hepatol. 31, 887-894

43 Avila, M. A., Berasain, C., Torres, L., Martin-Duce, A., Corrales, F. J., Yang, H., Prieto, J., Lu, S. C., Caballeria, J., Rodes, J. and Mato, J. M. (2000) Reduced mRNA abundance of the main enzymes involved in methionine metabolism in human liver cirrhosis and hepatocellular carcinoma. J. Hepatol. 33, 907-914

44 Hillary, R. A. and Pegg, A. E. (2003) Decarboxylases involved in polyamine biosynthesis and their inactivation by nitric oxide. Biochim. Biophys. Acta 1647, 161-166

45 Endo, Y. (1982) Simultaneous induction of histidine and ornithine decarboxylases and changes in their product amines following the injection of Escherichia coli lipopolysaccharide into mice. Biochem. Pharmacol. 31, 1643-1647

46 Droge, W. (2002) Free radicals in the physiological control of cell function. Physiol. Rev. 82, 47-95

47 Kadariya, Y., Nishioka, J., Nakamura, A., Kato-Nakazawa, K. and Nobori, T. (2003) Molecular characterization of 5'-deoxy-5'-methylthioadenosine phosphorylasedeficient mutant clones of murine lymphoma cell line R1.1. Cancer Sci. 94, 519-522

48 Salmeen, A., Andersen, J. N., Myers, M. P., Meng, T. C., Hinks, J. A., Tonks, N. K. and Barford, D. (2003) Redox regulation of protein tyrosine phosphatase $1 \mathrm{~B}$ involves a sulphenyl-amide intermediate. Nature 423, 769-773

49 van Montfort, R. L., Congreve, M., Tisi, D., Carr, R. and Jhoti, H. (2003) Oxidation state of the active-site cysteine in protein tyrosine phosphatase 1B. Nature $\mathbf{4 2 3}$ 773-777 